\title{
Profiles of Volatile and Phenolic Compounds as Markers of Ripening Stage in Candonga Strawberries
}

\author{
Rosaria Cozzolino ${ }^{1, *}$, , Bernardo Pace ${ }^{2, *}{ }^{10}$, Michela Palumbo ${ }^{2,3}$, Carmine Laurino ${ }^{1}$, Gianluca Picariello ${ }^{1}$, \\ Francesco Siano ${ }^{1}\left(\mathbb{D}\right.$, Beatrice De Giulio ${ }^{1}\left(\mathbb{D}\right.$, Sergio Pelosi ${ }^{2}$ and Maria Cefola ${ }^{2}$ \\ 1 Institute of Food Science, National Research Council (CNR), Via Roma 64, 83100 Avellino, Italy; \\ carmine.laurino@isa.cnr.it (C.L.); gianluca.picariello@isa.cnr.it (G.P.); francesco.siano@isa.cnr.it (F.S.); \\ beatrice.degiulio@isa.cnr.it (B.D.G.) \\ 2 Institute of Sciences of Food Production, National Research Council of Italy (CNR), c/o CS-DAT, Via M. Protano, \\ 71121 Foggia, Italy; michela.palumbo@ispa.cnr.it (M.P.); sergio.pelosi@ispa.cnr.it (S.P.); \\ maria.cefola@ispa.cnr.it (M.C.) \\ 3 Department of Agriculture, Food, Natural Resources and Engineering, University of Foggia, Via Napoli 25, \\ 71122 Foggia, Italy \\ * Correspondence: rosaria.cozzolino@isa.cnr.it (R.C.); bernardo.pace@ispa.cnr.it (B.P.)
}

Citation: Cozzolino, R.; Pace, B.; Palumbo, M.; Laurino, C.; Picariello, G.; Siano, F.; De Giulio, B.; Pelosi, S.; Cefola, M. Profiles of Volatile and Phenolic Compounds as Markers of Ripening Stage in Candonga Strawberries. Foods 2021, 10, 3102. https://doi.org/10.3390/foods10123102

Academic Editor: Jinhe Bai

Received: 12 November 2021 Accepted: 9 December 2021

Published: 14 December 202

Publisher's Note: MDPI stays neutral with regard to jurisdictional claims in published maps and institutional affiliations.

Copyright: (c) 2021 by the authors. Licensee MDPI, Basel, Switzerland. This article is an open access article distributed under the terms and conditions of the Creative Commons Attribution (CC BY) license (https:// creativecommons.org/licenses/by/ $4.0 /)$.
Abstract: Volatile compounds, quality traits (total phenols and antioxidant capacity) and Highperformance liquid chromatography (HPLC)-isolated polyphenols of strawberries, variety Sabrosa, commercially referred to as "Candonga", harvested at three different times (H1, H2 and H3) and at two different ripening stages, namely half-red (Half-red-H1, Half-red-H2 and Half-red-H3) and red (Red-H1, Red-H2 and Red-H3) were evaluated. Dominant anthocyanins, namely cyanidin-3$O$-glucoside, pelargonidin-3-O-glucoside and pelargonidin-3-O-rutinoside, as well as $p$-coumaryl hexoside increased during harvesting, differently from flavonoids, such as quercetin-3-O-glucoside, kaempferol-3-O-glucoronide and quercetin 3-O-glucoronide, that declined. Samples clustered in different quadrants of the principal component analysis (PCA) performed on volatiles, quality traits and phenolic compounds, highlighting that only the red samples were directly correlated to volatile components, as volatiles clearly increased both in number and amount during ripening. In particular, volatiles with a positive impact on the consumers' acceptance, including butyl butyrate, ethyl hexanoate, hexyl acetate, nonanal, terpenes and lactones, were positively associated with the Red-H1 and Red-H2 strawberries, while volatiles with negative coefficients related to consumer liking, including isopropyl butyrate, isoamyl butyrate and mesifurane directly correlated with the Red-H3 samples. Accordingly, strawberries harvested at Red-H1 and Red-H2 ripening stages could be preferred by the consumers compared to the Red-H3 fruit. Altogether, these results could help to individuate quality traits as putative markers of the ripening stage, and optimize the process of post-harvesting ripening to preserve or improve the desirable aromatic characteristics of strawberries.

Keywords: Fragaria $\times$ ananassa Duch.; Sabrosa; ripening stage; headspace solid phase microextraction (HS SPME GC/MS); HPLC-MS/MS principal component analysis

\section{Introduction}

Strawberry (Fragaria $\times$ ananassa Duch.) belongs to the Rosaceae family, and is one of the most commonly consumed berry fruit and cash crops worldwide, with more than 2000 varieties [1]. Because of the high content of ellagic acid (EA) and its precursors, strawberries are considered functional foods [1].

The functional traits of the strawberry originate from to the combination of vitamin $\mathrm{C}$ and other antioxidant components, primarily flavonoids, anthocyanins and EA. In spite of their relative low content (0.001-0.01\% of fresh fruit weight), the volatile organic compounds (VOCs) are the main responsible for the strawberries' flavor, which is a crucial factor in determining the consumer's preference and the sensory quality of the fruit [2-4]. 
Strawberry fruit can be considered a typical example of a complex fruit aroma, since several hundred VOCs concur to determine the flavor of fresh strawberries [4].

Qualitative and quantitative profiles of strawberry VOCs stem partially from genetic traits and growth-dependent activation of specific metabolic pathways, so that they show specific patterns and distinctive volatile components depending on the cultivar and degree of ripening [5]. Thus, aroma can be a fingerprint to distinguish among varieties and stage of fruit development [3].

The content of VOCs increases during the maturation in climacteric fruits, and a similar effect could be expected in non-climacteric fruit as well, such as the strawberry [3].

Harvesting fruit before it is fully ripe is a common practice for many fruits in the supply chain, as it allows to complete ripening in post-harvest storage [6].

Clearly, the maturity stage affects the consumer liking of these fruits, including strawberries, as a consequence of the changes affecting the volatile profile [7].

Monitoring the VOCs pattern during the maturation process could offer specific markers for establishing the optimal harvest time, ensuring a standardized aroma to consumers as well as maximizing quality and phytosanitary characteristics, thus contributing to minimizing post-harvest losses [5]. Volatile esters are the compounds most associated with strawberry fruit ripening, although VOCs belonging to different classes could be considered markers of maturity, varying with the cultivar [3].

Among the phenolic compounds, anthocyanins are responsible for the bright red color of the strawberries. They are the most abundant phenolic compounds in most of the 27 cultivars analyzed by Aaby et al. [8], and are known to possess health benefits. The anthocyanins also vary with cultivars, and steadily increase during ripening, as assessed by analyzing the number of strawberry cultivars [8].

The present study aimed at evaluating for the first time the changes in fruit quality traits, content of VOCs and phenolic compounds in strawberry samples of the variety Sabrosa, commercially referred to as "Candonga". Strawberries were collected at two different ripening stages (half-red and red) in three different harvesting times. The goal was to gain information about the modification at a metabolite level occurring during strawberry maturation and the contributing individuate putative molecular markers, in order to optimize the selection of the timing of harvest.

\section{Materials and Methods}

\subsection{Plant Material}

"Candonga" strawberries (Fragaria $\times$ ananassa Duch. var. Sabrosa) were harvested by Apofruit (Scanzano Jonico, Italy) on 21 May (first harvest time, H1), 27 May (second harvest time, H2) and 1 June (third harvest time, H3) at two different ripening stages, namely half-red (in ripening phase, fully expanded and 50\% red, indicated as Half-red-H1, Half-red-H2 and Half-red-H3) and red (in ripening phase, fully expanded and $100 \%$ red, indicated as Red-H1, Red-H2 and Red-H3), according to visual criteria (Figure 1).

Half-red and red strawberries showed soluble solids at harvest of about $8.8 \pm 0.7$ and $9.8 \pm 0.2{ }^{\circ}$ Brix, respectively. At each harvest time, fruit berries were packed into PET trays (Cartonpack spa, Rutigliano, Ba) (about $500 \mathrm{~g}$ for each tray) and transported in refrigerated conditions $\left(4 \pm 1{ }^{\circ} \mathrm{C}\right)$ to the Consiglio Nazionale delle Ricerche (CNR) laboratories, and were analyzed within $3 \mathrm{~h}$ since harvesting. Here, strawberries were visually inspected and selected to choose fruits free of physical or biological damage. Respiration rate titratable acidity, total soluble solids, $\mathrm{pH}$, color parameters, antioxidant activity, total phenols, HPLCseparated individual phenolic compounds and VOCs were evaluated at each harvest time and for each ripening stage. 


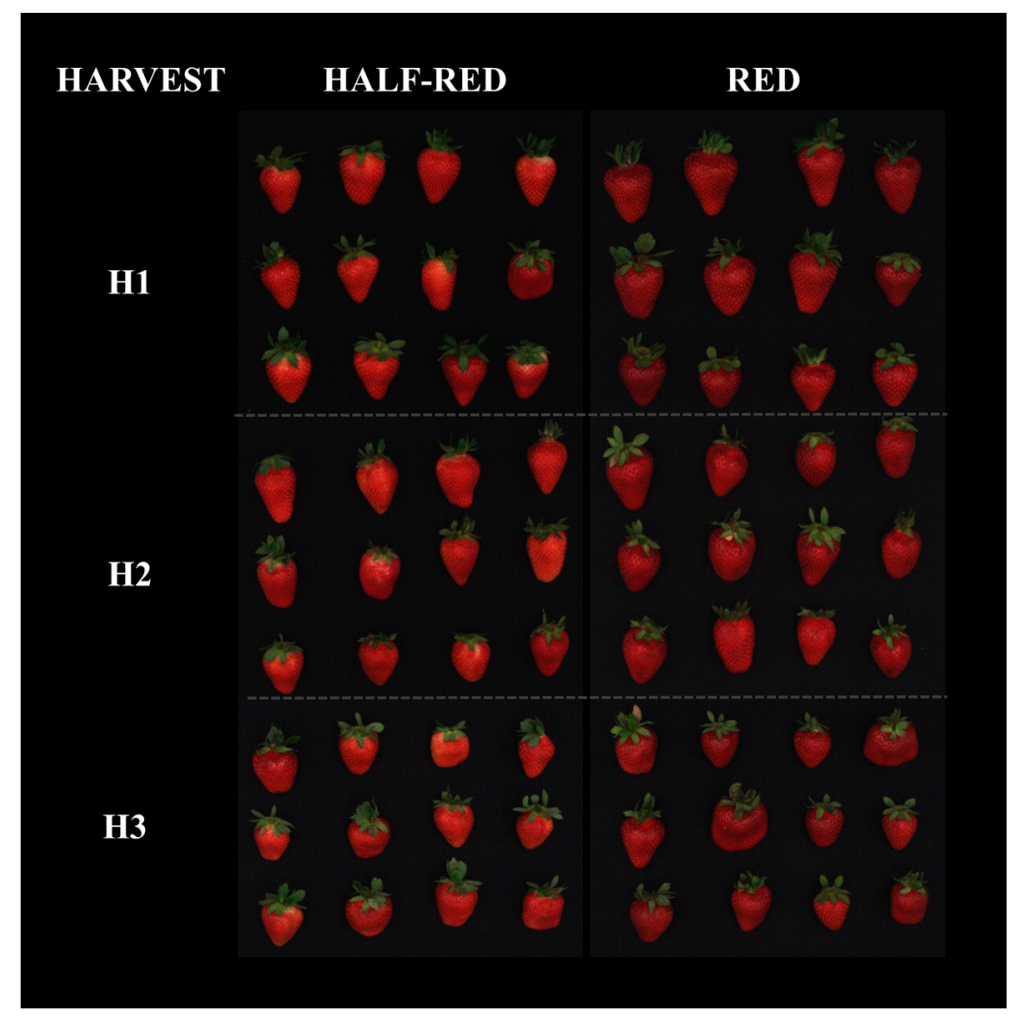

Figure 1. "Candonga" strawberries (var. Sabrosa) harvested at two different ripening stages, namely half-red (in ripening phase, fully expanded and 50\% red, indicated as Half-red-H1, Half-red-H2 and Half-red-H3) and red (in ripening phase, fully expanded and $100 \%$ red, indicated as Red-H1, Red-H2 and Red-H3).

\subsection{Reagents and Chemicals}

Chemicals, standards and reagents were from Sigma-Aldrich (St. Louis, MO, USA). Folin-Ciocalteu's phenol reagent was purchased from Merck (Darmstadt, Germany). Ultrapure water (resistivity at $25^{\circ} \mathrm{C}$ of $18 \mathrm{M} \Omega \mathrm{cm}$ ) was from a Millipore Milli-Q purification system (Millipore Corp., Bedford, MA, USA), while helium at a purity of $99.999 \%$ (Rivoira, Milan, Italy) was used as GC carrier gas. The HS-SPME fibers and the glass vials were purchased from Supelco (Bellofonte, PA, USA); the capillary GC-MS column High Polarity (HP)-Innowax $(30 \mathrm{~m} \times 0.25 \mathrm{~mm} \times 0.5 \mu \mathrm{m})$ was acquired from Agilent $\mathrm{J} \& W$ (Agilent Technologies Inc., Santa Clara, CA, USA).

\subsection{Respiration Rate}

The respiration rate of strawberries was measured at $8{ }^{\circ} \mathrm{C}$ using a closed system, according to the method reported by Kader [9]. In particular, for each ripening stage and replicate $(n=3)$, about $500 \mathrm{~g}$ of sample were put into $3.6 \mathrm{~L}$ sealed plastic jar (one jar for each replicate) where $\mathrm{CO}_{2}$ was allowed to accumulate up to $0.1 \%$ of the standard concentration of the $\mathrm{CO}_{2}$. The time taken to get to this value was detected by measuring the $\mathrm{CO}_{2}$ amounts at regular intervals of time. The $\mathrm{CO}_{2}$ analysis was conducted by injecting $1 \mathrm{~mL}$ of gas sample from the headspace of the plastic jars through a rubber septum into a gas chromatograph (p200 micro GC-Agilent, Santa Clara, CA, USA) fitted with dual columns and a thermal conductivity detector. $\mathrm{CO}_{2}$ was analyzed with a retention time of $16 \mathrm{~s}$ and a total run time of $120 \mathrm{~s}$ using a $10 \mathrm{~m}$ porous polymer (PPU) column (Agilent, Santa Clara, CA, USA) at a constant temperature of $70^{\circ} \mathrm{C}$. Respiration rate was reported as $\mathrm{mL} \mathrm{CO}_{2} / \mathrm{kg} \mathrm{h}$. 


\subsection{Total Soluble Solids, Titratable Acidity and $p H$}

For each replicate and at each ripening stage, about $100 \mathrm{~g}$ of strawberries was homogenized to obtain the fruit juice which was used to assay total soluble solids (TSS), titratable acidity (TA) and $\mathrm{pH}$. The TSS content was determined using a digital refractometer (DBR35XS Instruments, Carpi, Italy) and results were expressed in ${ }^{\circ}$ Brix.

The $\mathrm{pH}$ of the fruit juice was determined using a $\mathrm{pH}$ meter (PH-Burette 24-Crison Instrument, Barcelona, Spain) and the titratable acidity (\% citric acid) was measured by titration using $0.1 \mathrm{M} \mathrm{NaOH}$ to the final $\mathrm{pH}$ 8.1, revealed with phenolphthalein as the indicator.

\subsection{Antioxidant Activity and Total Phenolic Content}

The analyses of the antioxidant activity (AA) and the total phenolic content (TPC) of strawberry samples were carried out on samples extracted as follows: for each replicate and at each ripening stage, $5 \mathrm{~g}$ of strawberries (chopped into small pieces) was homogenized in $20 \mathrm{~mL}$ methanol/water solution $(80: 20 \mathrm{v} / \mathrm{v})$ for $2 \mathrm{~min}$, using a homogenizer (T-25 digital ULTRA-TURRAX ${ }^{\circledR}$-IKA, Staufen, Germany) and then centrifuged (Prism C2500-R, Labnet, Edison, NJ, USA) at $15,000 \mathrm{rpm}$ for $5 \mathrm{~min}$ at $4{ }^{\circ} \mathrm{C}$. The extracts were collected and stored at $-20^{\circ} \mathrm{C}$ before the analysis.

The AA was measured on the methanol extract using the DPPH (1,1-diphenyl-2picrylhydrazyl) assay as described by Cefola et al. [10]. The absorbance was measured at $515 \mathrm{~nm}$ after $40 \mathrm{~min}$ in the dark, using a spectrophotometer (UV-1800, Shimadzu, Kyoto, Japan). The results were expressed as mg of Trolox per $100 \mathrm{~g}$ of fw (fresh weight) using a Trolox calibration curve $\left(82-625 \mu \mathrm{M} ; \mathrm{R}^{2}=0.999\right)$.

The TPC was determined according to Fadda et al. [11]. In detail, $100 \mu \mathrm{L}$ of each extract was mixed into $1.58 \mathrm{~mL}$ of water, $100 \mu \mathrm{L}$ of Folin-Ciocalteu's reagent and $300 \mu \mathrm{L}$ of sodium carbonate solution $(200 \mathrm{~g} / \mathrm{L})$. The resulting absorbance was measured at $765 \mathrm{~nm}$ after $2 \mathrm{~h}$ in the dark and the results were expressed as mg of gallic acid equivalents (GAE) per $100 \mathrm{~g}$ of fw. The calibration curve of gallic acid was prepared with five points, from 50 to $500 \mu \mathrm{g} / \mathrm{mL}$, with $\mathrm{R}^{2}=0.998$.

\subsection{Analysis of Polyphenols Compounds}

2.6.1. Reversed Phase-High Performance Liquid Chromatographic-Diode Array Detector (RP-HPLC-DAD) Semi-Quantitative Determination of Polyphenols

Strawberry methanolic $(80 \%, v / v)$ extracts, prepared as described above (Par. 2.5), were ten-fold diluted with aqueous $0.1 \%(v / v)$ trifluoroacetic acid (TFA) and $100 \mu \mathrm{L}$ of the diluted sample was separated using a modular HP 1100 chromatographer (Agilent Technologies, Paolo Alto, CA, USA) equipped with a $250 \times 2.0 \mathrm{~mm}$ i.d. C18 reversed-phase column, $4 \mathrm{~mm}$ particle diameter (Jupiter Phenomenex, Torrance, CA, USA) held at $37^{\circ} \mathrm{C}$ in a thermostatic oven. HPLC runs were performed at a constant flow rate of $0.2 \mathrm{~mL} / \mathrm{min}$ applying the following gradient of solvent B: isocratic elution at $5 \%$ B for $5 \mathrm{~min}, 5-60 \%$ linear gradient of B for 5-65 min and $60-100 \%$ B at $65-70 \mathrm{~min}$. Eluent A and B were $0.1 \%$ TFA in HPLC-grade water and 0.1\% TFA in acetonitrile, respectively. Samples were run in triplicate and monitored at wavelengths $\lambda=520,360,320$ and $280 \mathrm{~nm}$ using a diode array detector (DAD), also acquiring a UV-Vis spectrum every second in the $200-700 \mathrm{~nm}$ range. A home-prepared multicomponent standard solution containing 15 (poly)phenols among which were gallic acid, $p$-coumaric acid, quercetin 3-O-glucoside, rutin, EA and quercetin and kaempferol aglycones (all from Sigma-Aldrich, St. Louis, MI, USA), was used to confirm or exclude the assignment of some phenolic compounds. Flavonoids were semi-quantified by plotting the area of peaks integrated at $360 \mathrm{~nm}$ on an external calibration curve built with standard rutin at a known concentration in the $0.10-5.00 \mu \mathrm{g} / \mathrm{mL}$ range $\left(R^{2}=0.99\right)$. Antocyanins and $p$-coumaryl-hexoside were semi-quantified based on calibration curves built with cyanidin-3-O-glucoside and $p$-coumaric acid with absorbance at 520 and $320 \mathrm{~nm}$, respectively. Data were processed using the ChemStation software 
(version A.10) purchased with the chromatograph. Analyses were carried out in triplicate and peak area values were averaged.

\subsubsection{Nanoflow HPLC-ESI MS/MS Analysis}

Identification of the phenolic compounds were confirmed by nanoflow-HPLC ESI MS/MS analysis, which was performed using an Ultimate 3000 ultra-high performance liquid chromatography instrument (Dionex/Thermo Scientific, San Jose, CA, USA), online coupled with a Q Exactive Orbitrap (Thermo Scientific) mass spectrometer, using previously detailed conditions [12]. The mass spectrometer switched between positive and negative ionization polarity in $1 \mathrm{~s}$ and scanned the $120-1200 \mathrm{~m} / \mathrm{z}$ range, and operated in datadependent acquisition for MS/MS, fragmenting up to 5 most intense signals in $1 \mathrm{~s}$ with $10 \mathrm{~s}$ of dynamic exclusion. Spectra were elaborated using the Xcalibur Software 3.1 version (Thermo Scientific).

\subsection{Volatile Organic Compounds (VOCs) Analysis}

\subsubsection{Sample Preparation and HS SPME Procedure}

The HS SPME conditions of analysis were optimized assaying strawberry samples obtained from a local supermarket. Profiling of VOCs was performed by HS SPME/GC-MS according to Zorrilla-Fontanesi et al. [13], but utilizing a DVB/CAR/PDMS (50/30 mm) fiber, with $50{ }^{\circ} \mathrm{C}$ as the extraction temperature and $20 \mathrm{~min}$ as the extraction time. Concerning the sample preparation, $1 \mathrm{~g}$ of "Candonga" strawberry sample was put into a $20 \mathrm{~mL}$ screw-on cap HS vial and mixed into $0.3 \mathrm{~g}$ of $\mathrm{NaCl}$. To ensure the analytical reproducibility, $1.5 \mu \mathrm{L}$ each sample was spiked with $20 \mathrm{ppm}$ of 2-octanol taken from a stock solution, used as the internal standard (IS). Vials were then sealed with a Teflon septum and an aluminum cap (Chromacol, Hertfordshire, UK) and stirred. The equilibration time and temperature were $10 \mathrm{~min}$ and $40^{\circ} \mathrm{C}$, respectively. The extraction and injection phases were automatically performed using an autosampler MPS 2 (Gerstel, Mülheim, Germany). Afterwards, the HS-SPME fiber was automatically introduced into the vial's septum for $20 \mathrm{~min}$ to allow VOCs to be adsorbed onto the fiber surface.

\subsubsection{Gas Chromatography-Quadrupole Mass Spectrometry Analysis (GC-qMS)}

VOC analysis was performed using a gas chromatograph model GC 7890A coupled to a mass spectrometer $5975 \mathrm{C}$ (system from Agilent Technologies, CA, USA). The HS SPME fiber was inserted for $10 \mathrm{~min}$ into the injector port of the GC instrument. VOCs were thermally desorbed and directly transferred to a capillary column HP-Innowax. Oven temperature conditions were initially set at $50{ }^{\circ} \mathrm{C}$ for $3 \mathrm{~min}$, then increased to $160{ }^{\circ} \mathrm{C}$ at $5{ }^{\circ} \mathrm{C} \mathrm{min}-1$, held at $160{ }^{\circ} \mathrm{C}$ for $1 \mathrm{~min}$, ramped to $250{ }^{\circ} \mathrm{C}$ at $10{ }^{\circ} \mathrm{C} \mathrm{min}^{-1}$ and stable at $250{ }^{\circ} \mathrm{C}$ for $2 \mathrm{~min}$. VOCs were analyzed at an ionization energy of $70 \mathrm{eV}$ and detected by mass selective detector. The detector operated in a mass range between 30 and $300 \mathrm{u}$ with a scanning speed of 2.7 scans/s. VOCs were identified by mass spectra through matching with the standard NIST05/Wiley07 libraries, by comparing the retention indices (RI) (as Kovats indices) with literature data and pure standards when available. Each sample was analyzed in triplicate with a randomized sequence in which blanks were also recorded. For each volatile component, the peak area was calculated from the total ion chromatogram (TIC) and semi-quantified by relative comparison with the peak area of the IS (Relative Peak Area, RPA\%).

\subsection{Statistical Data Analysis}

For each harvest, the effect of the ripening stage (half-red or red) on respiration rate, TA, TSS, $\mathrm{pH}, \mathrm{AA}, \mathrm{TPC}$ and VOCs was evaluated by performing a one-way Analysis of variance (ANOVA)for $p \leq 0.05$. The mean values $(n=3)$ were separated using the least significant difference (LSD) test $(p \leq 0.05)$, and Statgraphics Centurion (version 18.1.12, Warrenton, VA, USA) was used for statistical analyses. 
To highlight the VOCs correlated to half-red and red strawberries, a principal component analysis (PCA) was carried out using the software Statistica version 6.0. (Statsoft Inc., Tulsa, OK, USA).

\section{Results and Discussion}

\subsection{Quality Traits in Half-Red and Red Strawberries}

Respiration rate did not significantly differ between the two ripening stages, presenting values of about $15.10 \pm 1.3 \mathrm{~mL} \mathrm{CO}_{2} \mathrm{~kg}^{-1} \mathrm{~h}^{-1}$, in line with those observed in the classification reported by Kader [14] (Table 1). As concerns the physical parameters, the one-way ANOVA showed statistically significant different values $(p \leq 0.0001)$ between the ripening stages at $\mathrm{H} 1, \mathrm{H} 2$ and $\mathrm{H} 3$. In detail, $\mathrm{TA}$ in red strawberries was lower than that detected in half-red samples in all harvest times. These results were consistent with the lower $\mathrm{pH}$ values detected in half-red strawberries compared to those of the red samples at all the harvest times (Table 1). The decrease in TA with the consequent increase in $\mathrm{pH}$ during the ripening has been previously explained by the conversion of organic acids into sugars in the course of the respiration process [15]. The ripening stage significantly influenced TSS at each harvest time, showing higher values $(13.8,14.5$ and $4.4 \%$ more in $\mathrm{H} 1, \mathrm{H} 2$ and $\mathrm{H} 3$, respectively) in red samples than in half-red ones (Table 1). Similar results of TA, pH and TSS have been already reported by Correia et al. [16] and Aguero et al. [17] in "Candonga" strawberries harvested in spring at full ripening.

Table 1. Physical and chemical parameters measured in strawberries cv "Sabrosa" at two different ripening stages (half-red or red) and at three harvest times (H1, H2, H3).

\begin{tabular}{|c|c|c|c|c|c|c|c|c|c|c|c|c|c|c|c|}
\hline \multirow{4}{*}{ Parameters } & \multicolumn{15}{|c|}{ Harvest Time } \\
\hline & \multicolumn{5}{|c|}{ H1 } & \multicolumn{5}{|c|}{$\mathrm{H} 2$} & \multicolumn{5}{|c|}{ H3 } \\
\hline & \multicolumn{15}{|c|}{ Ripening Stage } \\
\hline & Red & & Half-Re & & $p$ & Red & & Half-Re & & $p$ & Red & & Half-Re & & $p$ \\
\hline Respiration rate $\left(\mathrm{mL} \mathrm{CO}_{2} \mathrm{~kg}^{-1} \mathrm{~h}^{-1}\right)$ & 16.74 & & 14.70 & & $\mathrm{~ns}$ & 15.33 & & 13.61 & & $\mathrm{~ns}$ & 16.50 & & 14.00 & & ns \\
\hline Titratable acidity (\% citric acid) & 0.78 & $\mathrm{~b}$ & 0.99 & a & $* * * *$ & 0.86 & $\mathrm{~b}$ & 1.00 & a & $* * * *$ & 0.76 & $\mathrm{~b}$ & 0.97 & a & $* * * *$ \\
\hline $\mathrm{pH}$ & 3.56 & a & 3.31 & $\mathrm{~b}$ & $* * * *$ & 3.44 & $\mathrm{a}$ & 3.27 & $\mathrm{~b}$ & $* * *$ & 3.54 & a & 3.46 & $\mathrm{~b}$ & * \\
\hline Total soluble solids ( ${ }^{\circ}$ Brix $)$ & 9.61 & $\mathrm{a}$ & 8.37 & $\mathrm{~b}$ & $* * *$ & 9.83 & $\mathrm{a}$ & 8.50 & $\mathrm{~b}$ & $* * * *$ & 10.17 & a & 9.73 & $\mathrm{~b}$ & $* *$ \\
\hline Antioxidant activity (mg Trolox $100 \mathrm{~g}^{-1} \mathrm{fw}$ ) & 314.72 & $\mathrm{a}$ & 345.06 & $\mathrm{~b}$ & $* * *$ & 308.12 & $\mathrm{~b}$ & 339.11 & a & $*$ & 287.5 & $\mathrm{~b}$ & 347.25 & $\mathrm{a}$ & $* * *$ \\
\hline Total phenols (mg GAE $100 \mathrm{~g}^{-1} \mathrm{fw}$ ) & 175.91 & $\mathrm{a}$ & 207.29 & $\mathrm{~b}$ & $*$ & 191.46 & $\mathrm{~b}$ & 218.05 & a & * & 183.42 & $\mathrm{~b}$ & 207.84 & $\mathrm{a}$ & $*$ \\
\hline
\end{tabular}

For each parameter the mean values followed by different letters $(\mathrm{a}, \mathrm{b})$ are significantly different $(p \leq 0.05)$ according to least significant difference (LSD) test. Significance: $\mathrm{ns}=$ not significant; ${ }^{* * * *}$ significant for $p \leq 0.0001$; ${ }^{* * *}$ significant for $p \leq 0.001$; ${ }^{* *}$ significant for $p \leq 0.01$; * significant for $p \leq 0.05$. GAE is Gallic Acid Equivalent.

The ripening stage of the strawberries significantly influenced AA, as half-red samples presented higher values $\left(345.06 \pm 4.2 \mathrm{mg}\right.$ Trolox $\left.100 \mathrm{~g}^{-1} \mathrm{fw}\right)$ than red berries $(287.46 \pm 14.2 \mathrm{mg}$ Trolox $100 \mathrm{~g}^{-1} \mathrm{fw}$ ), considering the mean of the three harvest times (Table 1). These findings are in line with previous determination of DPPH radical scavenging capacity $[18,19]$.

Analysis of TPC conducted on the strawberry samples at all the three harvest times mirrored the trend of AA, confirming that the AA values are directly related to the TPC, as already recorded in several fruit and vegetable crops [20-22]. Specifically, the half-red fruits displayed a TPC of $13.9 \%$ higher than the one detected on the red samples (Table 1), according to previous reports $[18,19]$.

\subsection{Phenolic Compounds in Half-Red and Red Strawberries}

The comprehensive pattern of polyphenols in the strawberry appears very complex, as compounds belonging to several classes, including hydroxycinnamic acid derivatives, flavonoids, and anthocyanins are variously represented. Despite numerous studies carried out to characterize strawberry metabolites, the current inventory of phenolic compounds emerging from the literature is controversial because of the large number of variety of cultivars available and the diversity of analytical methods employed. Nevertheless, the 
fraction is substantially dominated by a few compounds, whereas a multitude of other metabolites occur at a minor abundance $[23,24]$. The RP-HPLC separation of phenolic compounds in strawberry methanol extracts has been monitored at multiple wavelengths. Typical RP-HPLC chromatograms of extracts from red (left A) and half-red (right B) "Candonga" strawberries are shown in Figure 2. In particular, in Figure 2, the HPLC chromatograms recorded at $280 \mathrm{~nm}$ for the general detection of phenolic compounds, at $360 \mathrm{~nm}$ for the selective detection of flavonoids and EA and at $520 \mathrm{~nm}$ for the diagnostic detection of anthocyanins are compared. The main HPLC peaks were assigned in Table 2, based on the converging indications coming from previous identification of strawberry phenolics [23-25] UV-Vis spectra acquired with the DAD, high-resolution MS and MS/MS spectra. In agreement with previous data, $p$-coumaryl-hexoside (peak 1, P1) was the most abundant hydroxycinnamic acid derivative of strawberry, better detected at $320 \mathrm{~nm}$ (not shown) because of the characteristic absorbance band centered at $315 \mathrm{~nm}$. In half-red strawberries, P1 was 3-/4-fold lower than in the red samples. Similar to other strawberry cultivars, the anthocyanin profile of the strawberry is substantially conserved among the cultivars [25]. Pelargonidin-3-O-rutinoside (P4) was the prevalent anthocyanin both in red and half-red strawberry samples, followed by less abundant pelargonidin-3-O-glucoside (P3) and cyanidin-3-O-glucoside (P2). However, the concentration of anthocyanins in unripe fruits was nearly half than the red counterpart. The chromatogram at $360 \mathrm{~nm}$ was dominated by quercetin-3-O-glucuronide (P7), which was more abundant in Half-red-H1 and Half-red-H2 than in the ripened counterpart. Strawberries have been generally described as fruits rich in EA; however, the content of free EA can vary in a wide range, depending on the cultivar as well as on a series of abiotic factors [26]. In the current strawberry samples, free EA was detected at concentrations lower than the limit of quantification, co-eluting with kaempferol-3-O-glucoside (peak 6, P6), as also confirmed with a separate injection of pure EA. MS and MS/MS analysis allowed to establish the presence of free EA and assess that it was slightly more intense in half-red than in ripe strawberry [25] (data not shown). No glycosylated derivatives of EA were detected among the main compounds by RP-HPLC, while EA conjugates (i.e., pentoside and hexoside) were detected both in half-red and red strawberry by ion extraction in the MS runs (data not shown). Several minor signals of relatively high molecular weight compounds detected by LCMS were likely ellagitannins that could be converted into EA by processing or chemical hydrolysis [25]. A detailed characterization of strawberry ellagitannins is challenging and requires dedicated investigations $[24,27]$.

Table 2. Assignment and semi-quantitative determination of phenolic compounds measured in strawberries cv "Sabrosa" at two different ripening stages (half-red or red) and at three harvest times (H1, H2, H3).

\begin{tabular}{|c|c|c|c|c|c|c|c|c|c|c|c|c|c|c|c|c|}
\hline \multirow{3}{*}{$\begin{array}{l}\text { Polyphenols } \\
\text { oumaryl hexoside }\end{array}$} & \multirow{3}{*}{$\begin{array}{c}\text { Code } \\
\text { P1 }\end{array}$} & \multicolumn{5}{|c|}{ H1 } & \multicolumn{5}{|c|}{$\mathrm{H} 2$} & \multicolumn{5}{|c|}{ H3 } \\
\hline & & \multicolumn{2}{|c|}{ Half-Red } & \multicolumn{2}{|c|}{ Red } & \multirow{2}{*}{$\frac{p}{* * * *}$} & \multicolumn{2}{|c|}{ Half-Red } & \multicolumn{2}{|c|}{ Red } & \multirow{2}{*}{$\frac{p}{* * * *}$} & \multicolumn{2}{|c|}{ Half-Red } & \multicolumn{2}{|c|}{ Red } & \multirow{2}{*}{$\frac{p}{* * * *}$} \\
\hline & & 9.6 & $\mathrm{~b}$ & 28.5 & $\mathrm{a}$ & & 11.4 & $\mathrm{~b}$ & 25.9 & a & & 12.7 & $\mathrm{~b}$ & 29.0 & a & \\
\hline cyanidin-3-O-glucoside & P2 & 1.8 & $\mathrm{~b}$ & 3.3 & $\mathrm{a}$ & $* * * *$ & 2.0 & $\mathrm{~b}$ & 3.8 & a & $* * *$ & 1.5 & $\mathrm{~b}$ & 3.1 & a & $* * *$ \\
\hline pelargonidin 3-O-glucoside & P3 & 25.1 & $\mathrm{~b}$ & 48.7 & a & $* * * *$ & 19.8 & $\mathrm{~b}$ & 42.6 & a & $* * * *$ & 22.4 & $\mathrm{~b}$ & 43.6 & a & $* * * *$ \\
\hline pelargonidin 3-O-rutinoside & P4 & 3.1 & $\mathrm{~b}$ & 5.6 & a & $* * * *$ & 2.4 & $\mathrm{~b}$ & 4.5 & a & $* * *$ & 3.5 & $\mathrm{~b}$ & 5.1 & a & $* * *$ \\
\hline quercetin-3-O-glucoside & P5 & 5.1 & $\mathrm{a}$ & 4.2 & $\mathrm{~b}$ & $* * * *$ & 4.1 & a & 3.6 & $b$ & * & 3.3 & $\mathrm{a}$ & 3.2 & $\mathrm{~b}$ & * \\
\hline kaempferol-3-O-glucoside & P6 & 2.1 & $\mathrm{~b}$ & 2.3 & $\mathrm{a}$ & * & 2.5 & $\mathrm{a}$ & 2.1 & $\mathrm{~b}$ & $* * *$ & 2.1 & $\mathrm{~b}$ & 2.3 & a & * \\
\hline quercetin-3-O-glucuronide & P7 & 20.2 & $\mathrm{a}$ & 17.0 & $\mathrm{~b}$ & $* * *$ & 18.6 & a & 15.8 & $\mathrm{~b}$ & $* * * *$ & 12.5 & $\mathrm{~b}$ & 14.1 & a & $* * *$ \\
\hline kaempferol-3-O-glucuronide & P8 & 2.9 & $\mathrm{~b}$ & 3.1 & a & $* *$ & 3.0 & $\mathrm{~b}$ & 3.4 & a & $* *$ & 2.5 & $\mathrm{~b}$ & 2.8 & a & $* *$ \\
\hline
\end{tabular}

For each parameter the mean values followed by different letters $(a, b)$ are significantly different $(p \leq 0.05)$ according to least significant difference (LSD) test. Significance: $\mathrm{ns}=$ not significant; ${ }^{* * * *}$ significant for $p \leq 0.0001$; ${ }^{* * *}$ significant for $p \leq 0.001$; ${ }^{* *}$ significant for $p \leq 0.01$; * significant for $p \leq 0.05$.

The semi-quantitative figures determined for the individual phenolic compounds were in line with most of the previous determinations reported by other authors [8]. 

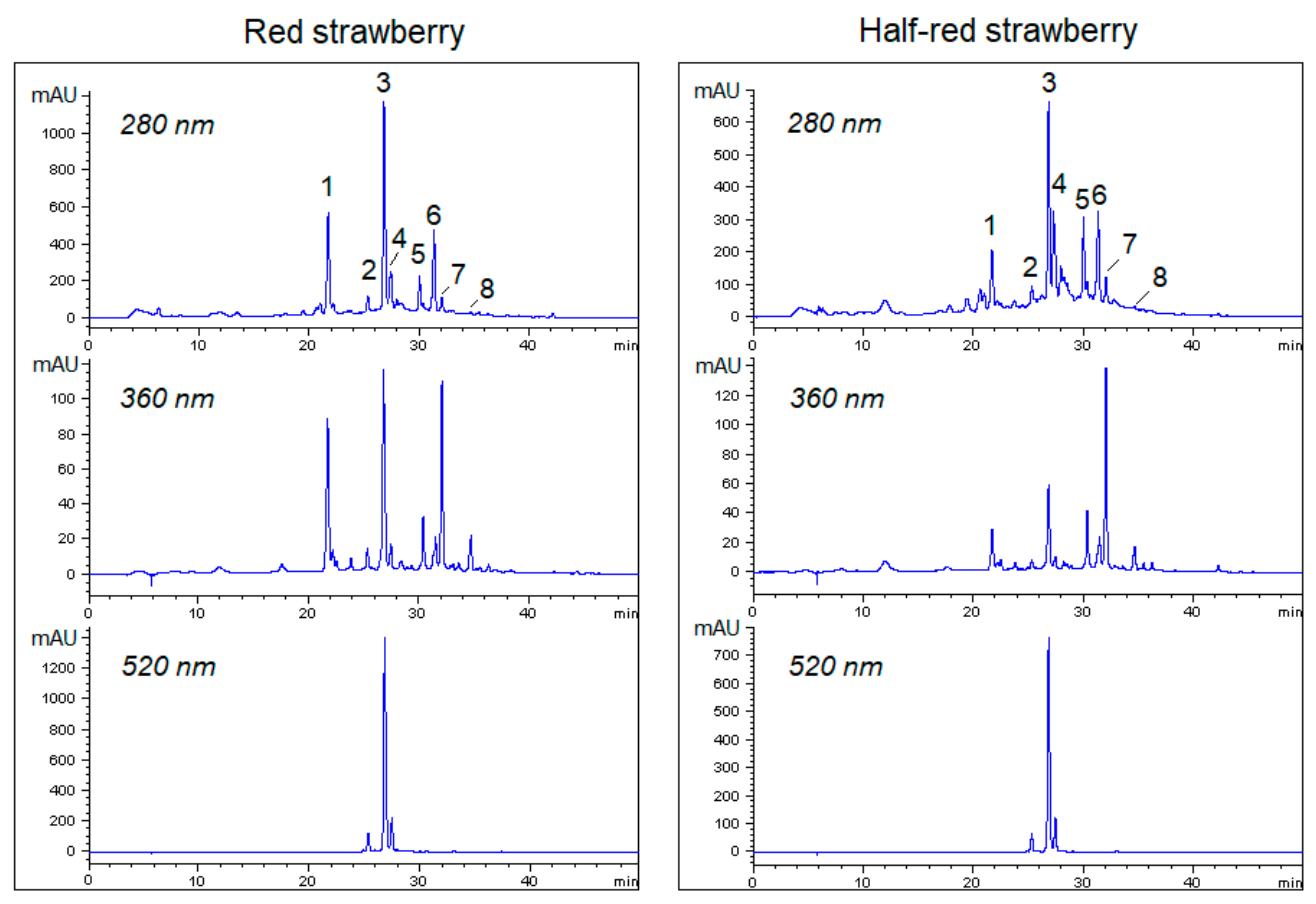

Figure 2. RP-HPLC chromatograms of extracts from red (left) and half-red (right) "Candonga" strawberries. Numbers (1-8) above the peaks correspond, respectively, to the codes P1-P8 reported on Table 2.

\subsection{VOCs Compounds in Half-Red and Red Strawberries}

3.3.1. Comparative Determination of VOCs in the "Candonga" Strawberry Samples at Two Different Ripening Stages

Overall, fifty-seven volatile compounds were identified by HS-SPME GC-MS analysis in the "Candonga" strawberry samples at two different ripening stages (half-red and red), and at three different harvest times which consisted of esters (26), aldehydes (5), alcohols (5), acids (9), terpenes (5), furanones (3), lactones (3) and others (1).

One-way ANOVA performed on the semi-quantitative data (RPA \%) evidenced significant qualitative and quantitative changes in the profile of VOCs over the course of the two maturation stages, as reported in Table 3. On the other hand, Table S1 includes the abbreviation code, the experimental and literature Kovats indexes and the identification methods for the assigned VOCs.

According to previous studies, ester compounds, responsible for the strawberry fruity and floral aroma, were the most abundant chemical class, with 18 and 26 different components accounting for about $37 \%$ and $49 \%$ of all the volatile compounds detected in the half-red and red fruit, respectively [3]. The majority of these esters have been previously reported in "Candonga" strawberries $[28,29]$. The most representative esters in half-red strawberries were methyl butyrate (E2) (37\%), methyl hexanoate (E9) $(27 \%)$ and trans-2-hexen-1-ol acetate (E16) (20\%), which increased up to about $40 \%$ of the total amount of esters in the red fruit. At ripening, together with $\gamma$-decalactone (L2), E16 became the component with the highest concentrations, individually constituting nearly $20 \%$ of the total content of the VOCs. These findings suggest that E16 and L2 could be considered as key indicators of full maturity in this variety (Table 3 ). 
Table 3. Volatile compounds obtained in strawberries cv "Sabrosa" at two different ripening stages (half-red or red) and at three harvest times (H1, H2, H3).

\begin{tabular}{|c|c|c|c|c|c|c|c|c|c|c|c|c|c|c|c|c|}
\hline \multirow[t]{3}{*}{ Volatile Componds } & \multicolumn{16}{|c|}{ Ripening Stage } \\
\hline & \multicolumn{5}{|c|}{ H1 } & \multicolumn{3}{|l|}{$\mathrm{H} 2$} & \multicolumn{7}{|c|}{ H3 } & \multirow[b]{2}{*}{$p$} \\
\hline & Code & \multicolumn{2}{|c|}{ Red } & \multicolumn{2}{|c|}{ Half-Red } & $p$ & \multicolumn{2}{|c|}{ Red } & \multicolumn{2}{|c|}{ Half-Red } & $p$ & \multicolumn{2}{|c|}{ Red } & \multicolumn{2}{|c|}{ Half-Red } & \\
\hline Methyl propionate & E1 & 1.92 & a & 0.91 & $\mathrm{~b}$ & $*$ & 2.65 & $\mathrm{a}$ & 0.94 & $\mathrm{~b}$ & $* * * *$ & 2.57 & $\mathrm{a}$ & 0.90 & $\mathrm{~b}$ & $* * * *$ \\
\hline Methyl butyrate & E2 & 682.95 & a & 246.38 & $\mathrm{~b}$ & $* * *$ & 806.88 & $\mathrm{a}$ & 256.15 & $\mathrm{~b}$ & $* * * *$ & 812.99 & $\mathrm{a}$ & 266.61 & $\mathrm{~b}$ & $* * * *$ \\
\hline Methyl isovalerate & E3 & 6.65 & a & 4.45 & $\mathrm{~b}$ & $* *$ & 7.70 & $\mathrm{a}$ & 3.97 & $\mathrm{~b}$ & $* * * *$ & 7.89 & $\mathrm{a}$ & 4.04 & $\mathrm{~b}$ & $* * * *$ \\
\hline Ethyl butyrate & $\mathrm{E} 4$ & 46.52 & a & 4.77 & $\mathrm{~b}$ & $*$ & 63.08 & $\mathrm{a}$ & 4.24 & $\mathrm{~b}$ & $* * * *$ & 61.06 & $\mathrm{a}$ & 4.29 & $\mathrm{~b}$ & $* * * *$ \\
\hline Isopropyl butyrate & E5 & 58.07 & a & 3.88 & $\mathrm{~b}$ & $* * * *$ & 73.39 & $\mathrm{a}$ & 3.62 & $\mathrm{~b}$ & $* * * *$ & 75.59 & $\mathrm{a}$ & 4.08 & $\mathrm{~b}$ & $* * * *$ \\
\hline Butyl acetate & E6 & 4.18 & a & 0.00 & $\mathrm{~b}$ & $* *$ & 4.77 & $\mathrm{a}$ & 0.00 & $\mathrm{~b}$ & $* * *$ & 5.99 & $\mathrm{a}$ & 0.00 & $\mathrm{~b}$ & $* * *$ \\
\hline Methyl pentanoate & E7 & 18.08 & a & 0.00 & $\mathrm{~b}$ & $* * * *$ & 28.53 & $\mathrm{a}$ & 0.00 & $\mathrm{~b}$ & $* * * *$ & 28.44 & $\mathrm{a}$ & 0.00 & $\mathrm{~b}$ & $* * * *$ \\
\hline Ethyl pentanoate & E8 & 1.75 & a & 0.00 & $\mathrm{~b}$ & $* *$ & 4.51 & $\mathrm{a}$ & 0.00 & $\mathrm{~b}$ & $* * * *$ & 4.63 & $\mathrm{a}$ & 0.00 & $\mathrm{~b}$ & $* * * *$ \\
\hline Methyl hexanoate & E9 & 472.43 & a & 188.74 & $\mathrm{~b}$ & $* *$ & 444.88 & $\mathrm{a}$ & 181.44 & $\mathrm{~b}$ & $* * * *$ & 465.00 & $\mathrm{a}$ & 182.94 & $\mathrm{~b}$ & $* * * *$ \\
\hline Butyl butyrate & E10 & 48.35 & $\mathrm{a}$ & 0.00 & $\mathrm{~b}$ & $* * * *$ & 48.95 & $\mathrm{a}$ & 0.00 & $\mathrm{~b}$ & $* * * *$ & 49.57 & $\mathrm{a}$ & 0.00 & $\mathrm{~b}$ & $* * * *$ \\
\hline Ethyl hexanoate & E11 & 219.48 & a & 0.00 & $\mathrm{~b}$ & $* * * *$ & 227.68 & $\mathrm{a}$ & 0.00 & $\mathrm{~b}$ & $* * * *$ & 278.43 & $\mathrm{a}$ & 0.00 & $\mathrm{~b}$ & $* * * *$ \\
\hline Isoamyl butyrate & E12 & 3.84 & a & 0.00 & $\mathrm{~b}$ & $* *$ & 5.76 & $\mathrm{a}$ & 0.00 & $\mathrm{~b}$ & $* * * *$ & 5.07 & $\mathrm{a}$ & 0.00 & $\mathrm{~b}$ & $* * * *$ \\
\hline Hexyl acetate & E13 & 473.52 & a & 35.15 & $\mathrm{~b}$ & $* * * *$ & 446.02 & $\mathrm{a}$ & 35.86 & $\mathrm{~b}$ & $* * * *$ & 441.31 & $\mathrm{a}$ & 35.77 & $\mathrm{~b}$ & $* * * *$ \\
\hline Methyl 2-hexenoate & E14 & 21.51 & a & 3.86 & $\mathrm{~b}$ & $* * * *$ & 21.07 & $\mathrm{a}$ & 3.48 & $\mathrm{~b}$ & $* * * *$ & 24.98 & a & 11.61 & $\mathrm{~b}$ & $* * * *$ \\
\hline cis-3-Hexen-1-ol acetate & E15 & 39.92 & a & 4.63 & $\mathrm{~b}$ & $* * * *$ & 39.40 & $\mathrm{a}$ & 3.97 & $\mathrm{~b}$ & $* * * *$ & 39.57 & $\mathrm{a}$ & 3.82 & $\mathrm{~b}$ & $* * * *$ \\
\hline trans-2-Hexen-1-ol propionate & E18 & 93.04 & a & 4.49 & $\mathrm{~b}$ & $* * * *$ & 91.79 & $\mathrm{a}$ & 4.51 & $\mathrm{~b}$ & $* * * *$ & 91.15 & $\mathrm{a}$ & 4.72 & $\mathrm{~b}$ & $* * * *$ \\
\hline n-Hexyl isobutyrate & E19 & 520.24 & a & 6.75 & $\mathrm{~b}$ & $* * * *$ & 515.75 & $\mathrm{a}$ & 6.89 & $\mathrm{~b}$ & $* * * *$ & 511.47 & $\mathrm{a}$ & 6.76 & $\mathrm{~b}$ & $* * * *$ \\
\hline trans-2-Hexenyl butyrate & E20 & 1114.73 & a & 21.94 & $\mathrm{~b}$ & $* * * *$ & 1107.06 & $\mathrm{a}$ & 21.32 & $\mathrm{~b}$ & $* * * *$ & 1080.35 & a & 21.21 & $\mathrm{~b}$ & $* * * *$ \\
\hline Methyl 3-(methylthio) propionate & E21 & 93.01 & a & 2.19 & $\mathrm{~b}$ & $* * * *$ & 91.28 & $\mathrm{a}$ & 2.33 & $\mathrm{~b}$ & $* * * *$ & 92.29 & $\mathrm{a}$ & 2.18 & $\mathrm{~b}$ & $* * * *$ \\
\hline Hexyl hexanoate & E22 & 4.29 & a & 1.18 & $\mathrm{~b}$ & $* * * *$ & 4.10 & $\mathrm{a}$ & 1.29 & $\mathrm{~b}$ & $* * * *$ & 4.48 & a & 1.40 & $\mathrm{~b}$ & $* * * *$ \\
\hline n-Octyl isobutyrate & E23 & 11.63 & a & 0.00 & $\mathrm{~b}$ & $* * * *$ & 11.31 & $\mathrm{a}$ & 0.00 & $\mathrm{~b}$ & $* * * *$ & 11.42 & a & 0.00 & $\mathrm{~b}$ & $* * * *$ \\
\hline Octyl 2-methylbutyrate & E24 & 4.03 & a & 0.00 & $\mathrm{~b}$ & $* * * *$ & 4.00 & $\mathrm{a}$ & 0.00 & $\mathrm{~b}$ & $* * * *$ & 4.00 & a & 0.00 & $\mathrm{~b}$ & $* * * *$ \\
\hline Methyl 3-hydroxyhexanoate & E25 & 4.62 & a & 1.67 & $\mathrm{~b}$ & $* * * *$ & 4.64 & $\mathrm{a}$ & 1.74 & $\mathrm{~b}$ & $* * * *$ & 4.07 & $\mathrm{a}$ & 1.73 & $\mathrm{~b}$ & $* * * *$ \\
\hline Benzyl acetate & E26 & 15.53 & a & 7.49 & $\mathrm{~b}$ & $* * * *$ & 15.66 & $\mathrm{a}$ & 7.66 & $\mathrm{~b}$ & $* * * *$ & 15.93 & $\mathrm{a}$ & 7.65 & $\mathrm{~b}$ & $* * * *$ \\
\hline Hexanal & Ald1 & 19.41 & a & 11.47 & $\mathrm{~b}$ & * & 33.11 & $\mathrm{a}$ & 11.96 & $\mathrm{~b}$ & $* * * *$ & 33.88 & $\mathrm{a}$ & 12.69 & $\mathrm{~b}$ & $* * * *$ \\
\hline 2-Hexenal & Ald2 & 532.42 & a & 234.98 & $\mathrm{~b}$ & $* * *$ & 503.36 & $\mathrm{a}$ & 221.54 & $\mathrm{~b}$ & $* * * *$ & 523.03 & $\mathrm{a}$ & 219.89 & $\mathrm{~b}$ & $* * * *$ \\
\hline Nonanal & Ald3 & 29.57 & a & 2.22 & $\mathrm{~b}$ & $* * * *$ & 26.25 & $\mathrm{a}$ & 2.46 & $\mathrm{~b}$ & $* * * *$ & 26.75 & $\mathrm{a}$ & 2.64 & $\mathrm{~b}$ & $* * * *$ \\
\hline Benzaldehyde & Ald4 & 76.65 & a & 5.12 & $\mathrm{~b}$ & $* * * *$ & 77.97 & $\mathrm{a}$ & 5.22 & $\mathrm{~b}$ & $* * * *$ & 77.14 & $\mathrm{a}$ & 5.37 & $\mathrm{~b}$ & $* * * *$ \\
\hline Dodecanal & Ald5 & 8.24 & a & 3.42 & $\mathrm{~b}$ & $* * * *$ & 8.08 & $\mathrm{a}$ & 3.66 & $\mathrm{~b}$ & $* * * *$ & 8.14 & $\mathrm{a}$ & 3.60 & $\mathrm{~b}$ & $* * * *$ \\
\hline 1-Hexanol & Al1 & 209.84 & a & 27.21 & $\mathrm{~b}$ & $* * * *$ & 209.38 & $\mathrm{a}$ & 28.10 & $\mathrm{~b}$ & $* * * *$ & 215.20 & $\mathrm{a}$ & 27.69 & $\mathrm{~b}$ & $* * * *$ \\
\hline trans-3-Hexen-1-ol & $\mathrm{Al} 2$ & 11.12 & a & 2.02 & $\mathrm{~b}$ & $* * * *$ & 11.08 & $\mathrm{a}$ & 2.11 & $\mathrm{~b}$ & $* * * *$ & 11.89 & $\mathrm{a}$ & 2.18 & $\mathrm{~b}$ & $* * * *$ \\
\hline
\end{tabular}


Table 3. Cont

\begin{tabular}{|c|c|c|c|c|c|c|c|c|c|c|c|c|c|c|c|c|}
\hline \multirow{3}{*}{\begin{tabular}{|c|} 
Volatile Componds \\
\\
cis-3-Hexen-1-ol \\
\end{tabular}} & \multicolumn{16}{|c|}{ Ripening Stage } \\
\hline & \multicolumn{5}{|c|}{ H1 } & \multicolumn{3}{|l|}{$\mathrm{H} 2$} & \multicolumn{5}{|c|}{ H3 } & & & \\
\hline & $\begin{array}{c}\text { Code } \\
\mathrm{Al} 3\end{array}$ & \multicolumn{2}{|c|}{ Red } & \multicolumn{2}{|c|}{ Half-Red } & $\frac{p}{* * * * *}$ & \multicolumn{2}{|c|}{ Red } & \multicolumn{2}{|c|}{ Half-Red } & $\frac{p}{* * * *}$ & \multicolumn{2}{|c|}{ Red } & \multicolumn{2}{|c|}{ Half-Red } & $\begin{array}{c}p \\
* * * *\end{array}$ \\
\hline trans-2-Hexen-1-ol & $\mathrm{Al} 4$ & 419.31 & a & 110.29 & $\mathrm{~b}$ & $* * * *$ & 404.16 & a & 111.24 & $\mathrm{~b}$ & $* * * *$ & 402.86 & $\mathrm{a}$ & 110.18 & $\mathrm{~b}$ & $* * * *$ \\
\hline 1-Octanol & Al5 & 3.47 & $\mathrm{a}$ & 1.31 & $\mathrm{~b}$ & $* * * *$ & 3.03 & $\mathrm{a}$ & 1.31 & $\mathrm{~b}$ & $* * * *$ & 3.32 & $\mathrm{a}$ & 1.69 & $\mathrm{~b}$ & $* * * *$ \\
\hline Propanoic acid & Ac1 & 37.29 & a & 1.56 & $\mathrm{~b}$ & $* * * *$ & 37.87 & $\mathrm{a}$ & 1.69 & $\mathrm{~b}$ & $* * * *$ & 37.72 & $\mathrm{a}$ & 1.78 & $\mathrm{~b}$ & $* * * *$ \\
\hline 2-Methylpropionic acid & Ac2 & 70.11 & $\mathrm{a}$ & 1.30 & $\mathrm{~b}$ & $* * * *$ & 70.47 & $\mathrm{a}$ & 1.30 & $\mathrm{~b}$ & $* * * *$ & 71.67 & $\mathrm{a}$ & 1.33 & $\mathrm{~b}$ & $* * * *$ \\
\hline 2-Methylbutanoic acid & Ac4 & 80.09 & a & 12.99 & $\mathrm{~b}$ & $* * * *$ & 88.70 & a & 12.82 & $\mathrm{~b}$ & $* * * *$ & 733.19 & $\mathrm{a}$ & 12.06 & $\mathrm{~b}$ & $* * * *$ \\
\hline Hexanoic acid & Ac5 & 1423.08 & $\mathrm{a}$ & 332.86 & $\mathrm{~b}$ & $* * * *$ & 1424.30 & $\mathrm{a}$ & 331.78 & $\mathrm{~b}$ & $* * * *$ & 1426.72 & $\mathrm{a}$ & 332.20 & $\mathrm{~b}$ & $* * * *$ \\
\hline Heptanoic acid & Ac6 & 33.53 & $\mathrm{a}$ & 4.26 & $\mathrm{~b}$ & $* * * *$ & 33.57 & $\mathrm{a}$ & 4.22 & $\mathrm{~b}$ & $* * * *$ & 33.89 & $\mathrm{a}$ & 4.32 & $\mathrm{~b}$ & $* * * *$ \\
\hline Octanoic acid & Ac7 & 35.88 & $\mathrm{a}$ & 5.99 & $\mathrm{~b}$ & $* * * *$ & 35.50 & $\mathrm{a}$ & 6.05 & $\mathrm{~b}$ & $* * * *$ & 35.56 & $\mathrm{a}$ & 6.19 & $\mathrm{~b}$ & $* * * *$ \\
\hline Nonanoic acid & Ac8 & 56.54 & $\mathrm{a}$ & 19.18 & $\mathrm{~b}$ & $* * * *$ & 56.05 & $\mathrm{a}$ & 19.35 & $\mathrm{~b}$ & $* * * *$ & 56.06 & $\mathrm{a}$ & 19.15 & $\mathrm{~b}$ & $* * * *$ \\
\hline Decanoic acid & Ac9 & 28.59 & $\mathrm{a}$ & 2.52 & $\mathrm{~b}$ & $* * * *$ & 29.25 & $\mathrm{a}$ & 2.50 & $\mathrm{~b}$ & $* * * *$ & 29.71 & $\mathrm{a}$ & 2.54 & $\mathrm{~b}$ & $* * * *$ \\
\hline Linalool & $\mathrm{T} 1$ & 111.83 & $\mathrm{a}$ & 62.76 & $\mathrm{~b}$ & $* * * *$ & 112.66 & $\mathrm{a}$ & 62.20 & $\mathrm{~b}$ & $* * * *$ & 112.18 & $\mathrm{a}$ & 62.92 & $\mathrm{~b}$ & $* * * *$ \\
\hline$\beta$-Farnesene & $\mathrm{T} 2$ & 11.12 & $\mathrm{a}$ & 0.00 & $\mathrm{~b}$ & $* * * *$ & 8.88 & $\mathrm{a}$ & 0.00 & $\mathrm{~b}$ & $* * * *$ & 11.75 & $\mathrm{a}$ & 0.00 & $\mathrm{~b}$ & $* * * *$ \\
\hline$\alpha$-Terpineol & $\mathrm{T} 3$ & 98.36 & $\mathrm{a}$ & 10.26 & $\mathrm{~b}$ & $* * * *$ & 98.21 & $\mathrm{a}$ & 10.86 & $\mathrm{~b}$ & $* * * *$ & 98.37 & $\mathrm{a}$ & 10.57 & $\mathrm{~b}$ & $* * * *$ \\
\hline Mesifurane & $\mathrm{F} 1$ & 140.90 & $\mathrm{a}$ & 12.89 & $\mathrm{~b}$ & $* * * *$ & 133.47 & $\mathrm{a}$ & 12.81 & $\mathrm{~b}$ & $* * * *$ & 1837.09 & $\mathrm{a}$ & 12.65 & $\mathrm{~b}$ & $* * * *$ \\
\hline Furaneol & $\mathrm{F} 2$ & 42.61 & $\mathrm{a}$ & 3.28 & $\mathrm{~b}$ & $* * * *$ & 41.99 & $\mathrm{a}$ & 3.26 & $\mathrm{~b}$ & $* * * *$ & 42.37 & $\mathrm{a}$ & 3.19 & $\mathrm{~b}$ & $* * * *$ \\
\hline trans- $\gamma$-Jasmolactone & F3 & 46.65 & $\mathrm{a}$ & 0.00 & $\mathrm{~b}$ & $* * * *$ & 46.69 & $\mathrm{a}$ & 0.00 & $\mathrm{~b}$ & $* * * *$ & 46.48 & $\mathrm{a}$ & 0.00 & $\mathrm{~b}$ & $* * * *$ \\
\hline$\gamma$-Octalactone & L1 & 4.31 & $\mathrm{a}$ & 0.00 & $\mathrm{~b}$ & $* * * *$ & 4.44 & $\mathrm{a}$ & 0.00 & $\mathrm{~b}$ & $* * * *$ & 4.57 & $\mathrm{a}$ & 0.00 & $\mathrm{~b}$ & $* * * *$ \\
\hline$\gamma$-Decalactone & $\mathrm{L} 2$ & 2689.87 & $\mathrm{a}$ & 262.49 & $\mathrm{~b}$ & $* * * *$ & 2631.41 & $\mathrm{a}$ & 260.20 & $\mathrm{~b}$ & $* * * *$ & 2660.37 & $\mathrm{a}$ & 260.14 & $\mathrm{~b}$ & $* * * *$ \\
\hline$\gamma$-Dodecalactone & L3 & 60.16 & $\mathrm{a}$ & 11.62 & $\mathrm{~b}$ & $* * * *$ & 61.88 & $\mathrm{a}$ & 11.00 & $\mathrm{~b}$ & $* * * *$ & 59.96 & $\mathrm{a}$ & 11.64 & $\mathrm{~b}$ & $* * * *$ \\
\hline Acetophenone & $\mathrm{O} 1$ & 4.42 & $\mathrm{a}$ & 0.00 & $\mathrm{~b}$ & $* * * *$ & 4.47 & $\mathrm{a}$ & 0.00 & $\mathrm{~b}$ & $* * * *$ & 4.52 & $\mathrm{a}$ & 0.00 & $\mathrm{~b}$ & $* * * *$ \\
\hline
\end{tabular}

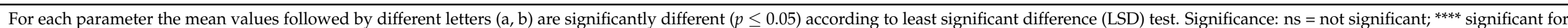

$p \leq 0.0001 ;{ }^{* * *}$ significant for $p \leq 0.001 ;{ }^{* *}$ significant for $p \leq 0.01 ;{ }^{*}$ significant for $p \leq 0.05$. 
Butyl acetate (E6), methyl pentanoate (E7), ethyl pentanoate (E8), butyl butyrate (E10), ethyl hexanoate (E11), isoamyl butyrate (E12), octyl isobutyrate (E23) and octyl 2-methylbutyrate (E24) were detected only in red berries (Table 3). In fruit, enzymatic biosynthesis of volatile esters through the esterification of alcohols and acyl-CoA, derived from both fatty acid and amino acid metabolism, occurs during the late ripening steps [30]. The enzyme responsible for the final step of ester formation is alcohol acyltransferase (AAT), which in strawberries can exhibit a 16-fold increase from the half-red to the full red ripeness degree [31]. A consistent correlation occurs among the expression of an AAT gene, AAT activity and concentrations of some volatile esters [31]. The availability of substrates for the biosynthesis of volatile esters is believed to be a limiting step in the production of esters, leading to different flavor profiles at each ripeness stage [30-32].

Five aldehyde compounds were common to the half-red and red stages, although occurring at a significantly higher concentration in full red berries (Table 3). The formation of $\mathrm{C} 6$ aldehydes originates from the lipid oxidation pathway, which involves lipoxygenase (LOX) and hydroperoxide lyase (HPL) enzymes. During ripening, the content of the two C6 aldehydes, namely hexanal (Ald1) and 2-hexenal (Ald 2), increases, paralleling the $25-200 \%$ increment in the activity of LOX and HPL enzymes and the availability of total linolenic acid as the precursor, which rises up to $200 \%$ [32].

Nonanal (Ald3) and decanal (Ald5), arising from the autoxidation of oleic acid, and benzaldehydes (Ald4), deriving from Strecker degradation of aromatic amino acids, increase during oxidative processes [33].

Gene expression studies reported the existence of a specific enzyme, O-methyltransferase, that is responsible for the synthesis of mesifurane (F1). Additionally, a Fragaria $\times$ ananassa quinine oxidoreductase $(\mathrm{FaQR})$ was documented to be involved in the formation of furaneol (F2). F1 and F2 increased considerably during ripening of strawberries, as the enzymes belonging to their biosynthetic pathway showed the maximum activity at the full red stage, allowing potential targets to engineer the strawberry flavor from breeding populations [31].

\subsubsection{Selection of the VOCs Correlated to Ripening Stage of Strawberry by Principal Component Analysis}

Principal component analysis (PCA) took into account AA, TPC, the semi-quantitative data of both individual phenolic compounds (Table 2) and VOCs (Table 3), to infer possible significant associations of strawberries at the two different ripening stages (half-red or red) and at the three harvesting times (Figure 3).

The two components accounted for $94.8 \%$ of the variation in the dataset, since PC1 and PC2 explained $90.3 \%$ and $4.5 \%$ of the total variance, respectively. In the PCA plot, all red samples (Red-H1, Red-H2 and Red-H3) appeared in the left part of the score plot, while all the half-red strawberries (Half-red-H1, Half-red-H2 and Half-red-H3) were positioned on the right part of the graph, revealing a different distribution of the samples in the PCA quadrants (Figure 3A). Specifically, Half-red-H1 and Half-red-H2 samples clustered closely in the bottom right part of the plot, having positive PC1 and negative PC2 values (Figure $3 \mathrm{~A}$ ). These samples showed a significant correlation with three phenolic compounds (P5, P6 and P7) and with AC (Figure 3B). The direct association of Halfred-H1 and Half-red-H2 samples with the P5, P6 and P7 metabolites likely reflects the decline in the synthesis of flavonoids during the last stage of ripening, as demonstrated for other fruits. The decrease in flavonoids might correspond to their utilization for the downstream biosynthesis of other metabolites, or to the covalent association with other cellular components [34]. Furthermore, a higher contribution of flavonoids compared to other classes of phenolic compounds could explain the correlation with AA.

On the contrary, Half-red-H3 fruit presented positive PC1 and PC2 scores (Figure 3A) and appeared statistically associated only with TPC (Figure 3B).

The strawberry samples classified as Red-H1 and Red-H2, with negative PC1 and PC2 scores, were grouped closely in the bottom left part of the PCA plot (Figure 3A) and covaried with the same volatile metabolites: 39 VOCs comprising 14 esters (E9, E10, E13, 
E15, E16, E17, E18, E19 E20, E21, E23, E24, E25, E26), 4 aldehydes (Ald2, Ald3, Ald4, Ald5), 3 alcohols (Al1, Al2, A14), 8 acids (Ac1, Ac2, Ac3, Ac5, Ac6, Ac7, Ac8, Ac9), 4 terpenes (T1, T3, T4, T5), 2 furanones (F2, F3), 3 lactones (L1, L2, L3) 1 other (O1) and 3 phenolic compounds (P2, P3 and P8) (Figure 3B).

In the PCA score plot, Red-H3 strawberries presented negative PC1 and positive PC2, and were placed in the high left section of the PCA plot (Figure 3A). This sample showed a significant correlation with 2 phenolic compounds (P1 and P4) and 18 VOCs, including 12 esters (E1, E2, E3, E4, E5, E6, E7, E8, E11, E12, E14, E22), 1 aldehydes (Ald1), 2 alcohols (A13 and A15), 2-methylbutyric acid (Ac4), $\beta$-farnesene (T2) and mesifurane (F1) (Figure 3B).

The correlation of anthocyanins (P2-P4) with red samples reflects the evident accumulation of these metabolites during ripening, which has been determined for the strawberry on a biosynthetic basis [35]. Interestingly, the increased production of P1 (i.e., $p$-coumaryl-glucoside, a conjugated monolignol) parallels the decline in flavonoids, since the $p$-coumaroyl-CoA precursor is common to the metabolic routes leading to either flavonoid or monolignol biosynthetic pathways. Thus, the downregulation of the flavonoid pathway corresponds to increased levels of monolignols deriving from the conversion of p-coumaroyl-CoA [36].

PCA clearly highlighted that only the red samples (Red-H1, Red-H2 and Red-H3) were directly correlated to volatile components (Figure 3B), in agreement with previous reports demonstrating a considerable increase both in number and content of VOCs during the ripening of strawberries [3,30-32]. In particular, Red-H1 and Red-H2 samples were statistically associated with a higher number of volatile metabolites (39) compared to Red-H3 strawberries (18) (Figure 3B).

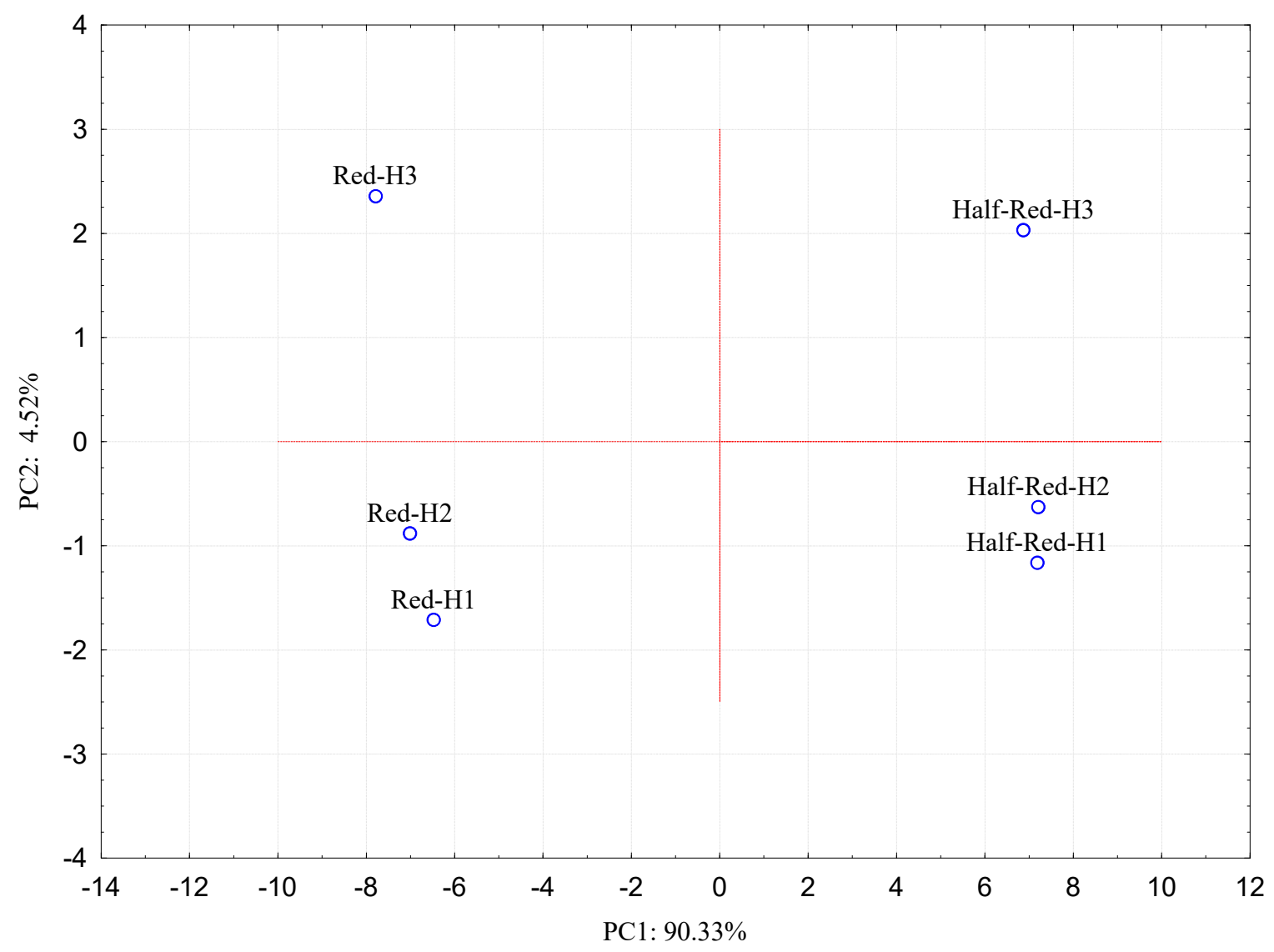

Figure 3. Cont. 


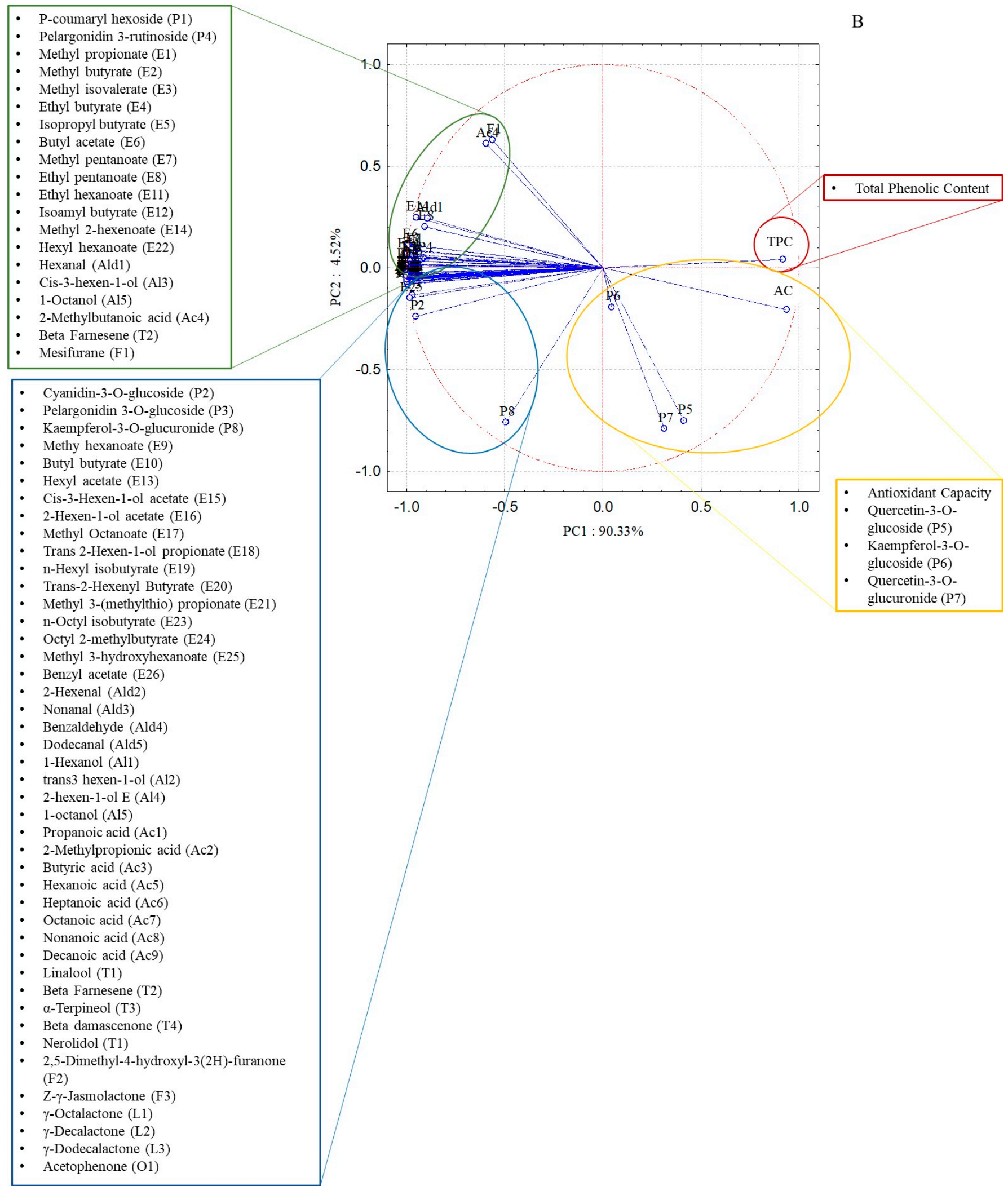

Figure 3. Principal component analysis (PCA) score (A) and loading (B) plots.

Ester compounds were the most affected by fruit ripening, and they actually characterize mature berries as they are responsible for fruity aromas. Nevertheless, only some of them may be useful as indicators of full ripeness [3]. Among the 14 esters positively 
associated with the Red-H1 and Red-H2 samples, trans-2-hexen-1-ol acetate (E16) and trans-2-hexenyl butyrate (E20) were the most abundant esters at the red stage (Table 3), while methyl hexanoate (E9) has been considered as a volatile marker related to the degree of maturity in different strawberry cultivars. Moreover, since it has been reported to be show its highest content in the full red strawberry, E9 has been closely associated with the flavor of mature strawberries [3]. On the other hand, methyl octanoate (E17) has been tentatively identified in the "Candonga" strawberries as responsible for the tropical/pineapple/citrus/green odor [29]. Finally, hexyl acetate (E13) has been previously described among the main contributors to the overall appreciation of strawberry quality [37].

Red-H1 and Red-H2 samples were statistically correlated to the aldehydes Ald2, Ald3, Ald4, Ald5 (Table 3; Figure 3B). Specifically, nonanal (Ald3) and benzaldehyde (Ald4) have been recently identified as volatiles, which enhance sweetness independently of the sugar content together with $\gamma$-decalactone (L2) and $\gamma$-dodecalactone (L3), which are among the three lactones directly correlated to the Red-H1 and Red-H2 samples (Figure 3B) [38,39]. Specifically, $\gamma$-decalactone (L2) gives the major contribution to the desirable "fruity", "sweet" or "peach-like" aroma in strawberries [40]. In general, several lactone compounds are commonly described as key odorants, determining the pleasant and fruity notes to strawberries [28].

Considering the nine carboxylic acids (Ac1, Ac2, Ac3, Ac5, Ac6, Ac7, Ac8 and Ac9) positively associated to the Red-H1 and Red-H2 samples, hexanoic acid (Ac5) was among the highest abundant odorants in strawberries at the red stage (Table 3). Ac5 has been identified as a key aroma compound of strawberry fruit [37].

Concerning the terpenes group, linalool (T1) also increased with ripeness (Table 3). To this purpose, previous studies pointed at this terpene as an indicator to measure the ripeness stage of fresh strawberry fruits, offering a valuable indication of ideal harvest timing. Nevertheless, it is important to underline that these findings might not be transferable to other cultivars [5].

Finally, among the volatile metabolites positively related to the Red-H1 and Red-H2 strawberries, there was furaneol (F2) already reported in several strawberry varieties, including "Candonga" [29]. F2 is considered a key aroma volatile in strawberry; it increases with ripening, conferring the characteristic caramel-like, sweet, floral, and fruity odor [29,41].

Regarding the 12 esters directly correlated to the Red-H3 strawberries (Figure 3B), methyl butyrate (E2), ethyl butyrate (E4), ethyl pentanoate (E8) and ethyl hexanoate (E11) have been reported as prominent components in several strawberry cultivars and historically recognized as crucial to the characteristic fruity notes of mature strawberries [41,42].

Among the volatile metabolites positively associated with the Red-H3 samples, there were also octanol (A15), previously reported in fruits at late stages of maturation, and mesifurane (F1), which is known to increase during the fruit ripening imparting a particular caramel or cotton candy-like odor in red strawberries [5,37].

Recent studies have established that specific VOCs can enhance both the flavor and the sweetness perception in fresh strawberries, evaluating the overall acceptance of strawberry fruit by the statistical correlations among sensory attributes, such as 'sweet' and 'aromatic', assessed by a consumers' panel, and analytical data, including the VOCs profile [38,42]. Regardless of the sugar-acid balance, VOCs with a positive impact on the consumers' acceptance generally are some esters, including E10, E11 and E13, some aldehydes, such as Ald3, terpenes and lactones, which in our study were positively associated with the Red-H1 and Red-H2 strawberries, while negative coefficients related to liking occur with branched esters, including E5 and E12, and mesifurane (F1), which are directly correlated to the Red-H3 samples (Figure 3B) [38,42]. According to these findings, the Red-H1 and Red-H2 harvesting times could be preferred by the consumers compared to the Red-H3 fruit. 


\section{Conclusions}

In this study, the changes in fruit quality traits, content of VOCs and phenolic compounds in strawberries (cv Sabrosa), commercially referred to as "Candonga", were evaluated at three consecutive harvesting times. Fruits collected at different times did not present significant differences among the determined qualitative traits, which, on the other hand, significantly differentiated the two ripening stages. Multivariate analysis carried out considering all the chemical data highlighted that Red-H1 and Red-H2 samples were similar to each other, while Red-H3 significantly differed, probably indicating overripe or an early stage of fruit involution. Some volatiles with a positive impact on the consumers' preference, including E10, E11, E13, Ald3, terpenes and lactones, were positively associated with the Red-H1 and Red-H2 samples, while volatiles with a detrimental contribution to the aroma traits, such as E5, E12 and F1, were directly correlated to the Red-H3 samples. However, although no univocal optimal patterns of volatile metabolites can be associated with a high level of acceptance, and taking into account that the contribution of individual VOCs to a typical aroma relies on both the aroma threshold value (ATV) and its concentration, a correlation between sensory parameters and the VOC patterns could help discover associations within the multiple factors of complex biosystems, such as fruit. For these reasons, the characterization of the VOCs related to the sensory perception of red or half-red samples of "Candonga" strawberries requires the integration with forthcoming experiments based on sensorial perception by a panel test.

In conclusion, the explorative results reported here might be of interest for producers, to identify putative markers useful for the objective assessment of the ripening stage, to optimize the strawberry harvest with the final aim to meet consumers' liking.

Supplementary Materials: The following are available online at https:/ / www.mdpi.com/article/ 10.3390 / foods10123102/s1, Table S1: Volatile metabolites detected in “Sabrosa" strawberries and their identification codes.

Author Contributions: Conceptualization, R.C., G.P., M.C. and B.P.; methodology, R.C., G.P. and F.S.; formal analysis, C.L., F.S., B.D.G., S.P. and M.P.; investigation, R.C. and G.P.; data curation, R.C., G.P., F.S., M.C. and M.P.; writing—original draft preparation, R.C., G.P. and M.C.; writing—review and editing, R.C., G.P., M.P., M.C. and B.P.; visualization, R.C. and G.P.; supervision, R.C., G.P. and M.C.; funding acquisition, B.P. and M.C. All authors have read and agreed to the published version of the manuscript.

Funding: This research was funded by the Project PON «R\&I» 2014-2020—Azione II—“E-cropsTechnologies for Digital and Sustainable Agriculture" funded by the Italian Ministry of University and Research (MUR) under the PON Agrifood Program (Contract ARS01_01136).

Data Availability Statement: The datasets generated for this study are available on request to the corresponding author.

Acknowledgments: Giuseppe Sicuro of APOFRUIT ITALIA Massimo Franchi and Mariella Quarto of CNR-ISPA for the technical and administrative support.

Conflicts of Interest: The authors declare no conflict of interest.

\section{References}

1. Zhao, J.; Liu, J.; Wang, F.; Wang, S.; Feng, H.; Xie, X.; Hao, F.; Zhang, L.; Fang, C. Volatile constituents and ellagic acid formation in strawberry fruits of selected cultivars. Food Res. Int. 2020, 138, 109767. [CrossRef] [PubMed]

2. Yan, J.W.; Ban, Z.J.; Lu, H.Y.; Li, D.; Poverenov, E.; Luo, Z.S.; Li, L. The aroma volatile repertoire in strawberry fruit: A review. J. Sci. Food Agric. 2018, 98, 4395-4402. [CrossRef] [PubMed]

3. Padilla-Jiménez, S.M.; Angoa-Pérez, M.V.; Mena-Violante, H.G.; Oyoque-Salcedo, G.; Montañez-Soto, J.L.; Oregel-Zamudio, E. Identification of Organic Volatile Markers Associated with Aroma during Maturation of Strawberry Fruits. Molecules 2021, $26,504$. [CrossRef] [PubMed]

4. Sheng, L.; Ni, Y.; Wang, J.; Chen, Y.; Gao, H. Characteristic- aroma-component-based evaluation and classification of strawberry varieties by aroma type. Molecules 2021, 26, 6219. [CrossRef] [PubMed]

5. Padilla-Jiménez, S.M.; Angoa-Pérez, M.V.; Mena-Violante, H.G.; Oyoque-Salcedo, G.; Renteria-Ortega, M.; Oregel-Zamudio, E. Changes in the Aroma of Organic Blackberries (Rubus fruticosus) During Ripeness. Anal. Chem. Lett. 2019, 9, 64-73. [CrossRef] 
6. Kader, A.A. Flavor quality of fruits and vegetables. J. Sci. Food Agric. 2008, 88, 1863-1868. [CrossRef]

7. Li, H.; Brouwer, B.; Oud, N.; Verdonk, J.C.; Tikunov, Y.; Woltering, E.; Schouten, R.; Pereira da Silva, F. Sensory, GC-MS and PTR-ToF-MS profiling of strawberries varying in maturity at harvest with subsequent cold storage. Postharvest Biol. Technol. 2021, 182, 111719. [CrossRef]

8. Aaby, K.; Mazur, S.; Nes, A.; Skrede, G. Phenolic compounds in strawberry (Fragaria x ananassa Duch.) fruits: Composition in 27 cultivars and changes during ripening. Food Chem. 2012, 132, 86-97. [CrossRef] [PubMed]

9. Kader, A.A. Methods of gas mixing, sampling and analysis. In Postharvest Technology of Horticultural Crops; Kader, A.A., Ed.; University of California Agriculture and Natural Resources: Oakland, CA, USA, 2002; pp. 145-148.

10. Cefola, M.; Pace, B.; Sergio, L.; Baruzzi, F.; Gatto, M.A.; Carito, A.; Linsalata, V.; Cascarano, N.A.; Di Venere, D. Postharvest performance of fresh-cut 'Big Top' nectarine as affected by dipping in chemical preservatives and packaging in modified atmosphere. Int. J. Food Sci. Technol. 2014, 49, 1184-1195. [CrossRef]

11. Fadda, A.; Pace, B.; Angioni, A.; Barberis, A.; Cefola, M. Suitability for ready-to-eat processing and preservation of six green and red baby leaves cultivars and evaluation of their antioxidant value during storage and after the expiration date. J. Food Process. Preserv. 2016, 40, 550-558. [CrossRef]

12. Picariello, G.; Sciammaro, L.; Siano, F.; Volpe, M.G.; Puppo, M.C.; Mamone, G. Comparative analysis of C-glycosidic flavonoids from Prosopis spp. and Ceratonia siliqua seed germ flour. Food Res. Int. 2017, 99, 730-738. [CrossRef]

13. Zorrilla-Fontanesi, Y.; Rambla, J.L.; Cabeza, A.; Medina, J.J.; Sánchez-Sevilla, J.F.; Valpuesta, V.; Botella, M.A.; Granell, A.; Amaya, I. Genetic analysis of strawberry fruit aroma and identification of O-methyltransferase FaOMT as the locus controlling natural variation in mesifurane content. Plant Physiol. 2012, 159, 851-870. [CrossRef]

14. Kader, A.A. Postharvest biology and technology: An overview. In Postharvest Technology of Horticultural Crops; Kader, A.A., Ed.; University of California Agriculture and Natural Resources: Oakland, CA, USA, 2002; pp. 39-47.

15. Janurianti, N.M.D.; Utama, I.M.S.; Gunam, I.B.W. Colour and quality of strawberry fruit (Fragaria $\mathrm{x}$ ananassa Duch.) at different levels of maturity. SEAS 2021, 5, 22-28. [CrossRef]

16. Correia, P.J.; Pestana, M.; Martinez, F.; Ribeiro, E.; Gama, F.; Saavedra, T.; Palencia, P. Relationships between strawberry fruit quality attributes and crop load. Sci. Hortic. 2011, 130, 398-403. [CrossRef]

17. Agüero, J.J.; Salazar, S.M.; Kirschbaum, D.S.; Jerez, E.F. Factors affecting fruit quality in strawberries grown in a subtropical environment. Int. J. Fruit Sci. 2015, 15, 223-234. [CrossRef]

18. Hwang, H.; Kim, Y.J.; Shin, Y. Influence of ripening stage and cultivar on physicochemical properties, sugar and organic acid profiles, and antioxidant compositions of strawberries. Food Sci. Biotechnol. 2019, 28, 1659-1667. [CrossRef] [PubMed]

19. Kim, Y.J.; Shin, Y. Antioxidant profile, antioxidant activity, and physicochemical characteristics of strawberries from different cultivars and harvest locations. J. Appl. Biol. Chem. 2015, 58, 587-595. [CrossRef]

20. Kandoliya, U.K.; Bajaniya, V.K.; Bhadja, N.K.; Bodar, N.P.; Golakiya, B.A. Antioxidant and nutritional components of eggplant (Solanum melongena L.) fruit grown in Saurastra region. Int. J. Curr. Microbiol. Appl. Sci. 2015, 4, 806-813.

21. Cefola, M.; Carbone, V.; Minasi, P.; Pace, B. Phenolic profiles and postharvest quality changes of fresh-cut radicchio (Cichorium intybus L.): Nutrient value in fresh vs. stored leaves. J. Food Comp. Anal. 2016, 51, 76-84. [CrossRef]

22. Capotorto, I.; Innamorato, V.; Cefola, M.; Cervellieri, S.; Lippolis, V.; Longobardi, F.; Logrieco, A.F.; Pace, B. High CO 2 short-term treatment to preserve quality and volatiles profile of fresh-cut artichokes during cold storage. Postharvest Biol. Technol. 2020, 160, 111056. [CrossRef]

23. Aaby, K.; Ekeberg, D.; Skrede, G. Characterization of phenolic compounds in strawberry (Fragaria $\times$ ananassa) fruits by different HPLC detectors and contribution of individual compounds to total antioxidant capacity. J. Agric. Food Chem. 2007, $30,4395$. [CrossRef]

24. La Barbera, G.; Capriotti, A.L.; Cavaliere, C.; Piovesana, S.; Samperi, R.; Zenezini Chiozzi, R.; Laganà, A. Comprehensive polyphenol profiling of a strawberry extract (Fragaria $\times$ ananassa) by ultra-high-performance liquid chromatography coupled with high-resolution mass spectrometry. Anal. Bioanal. Chem. 2017, 409, 2127-2142. [CrossRef]

25. Truchado, P.; Larrosa, M.; García-Conesa, M.T.; Cerdá, B.; Vidal-Guevara, M.L.; Tomás-Barberán, F.A.; Espín, J.C. Strawberry processing does not affect the production and urinary excretion of urolithins, ellagic acid metabolites, in humans. J. Agric. Food Chem. 2012, 60, 5749-5754. [CrossRef] [PubMed]

26. Williner, M.R.; Pirovani, M.E.; Güemes, D.R. Ellagic acid content in strawberries of different cultivars and ripening stages. J. Sci. Food Agric. 2003, 83, 842-845. [CrossRef]

27. Seeram, N.P.; Lee, R.; Scheuller, H.S.; Heber, D. Identification of phenolic compounds in strawberries by liquid chromatography electrospray ionization mass spectroscopy. Food Chem. 2006, 97, 1-11. [CrossRef]

28. González-Domínguez, R.; Sayago, A.; Akhatou, I.; Fernández-Recamales, Á. Volatile profiling of strawberry fruits cultivated in a soilless system to investigate cultivar-dependent chemical descriptors. Foods 2020, 9, 768. [CrossRef] [PubMed]

29. Ubeda, C.; San-Juan, F.; Concejero, B.; Callejón, R.M.; Troncoso, A.M.; Morales, M.L.; Ferreira, V.; Hernández-Orte, P. Glycosidically bound aroma compounds and impact odorants of four strawberry varieties. J. Agric. Food Chem. 2012, 60, 6095-6102. [CrossRef] [PubMed]

30. Zhu, X.; Li, Q.; Li, J.; Luo, J.; Chen, W.; Li, X. Comparative study of volatile compounds in the fruit of two banana cultivars at different ripening stages. Molecules 2018, 23, 2456. [CrossRef] [PubMed]

31. Song, J.; Forney, C.F. Flavour volatile production and regulation in fruit. Can. J. Plant Sci. 2008, 88, 537550. [CrossRef] 
32. Ozcan, G.; Barringer, S. Effect of enzymes on strawberry volatiles during storage, at different ripeness level, in different cultivars and during eating. J. Food Sci. 2011, 71, C324-C333. [CrossRef]

33. Xu, L.; Yu, X.; Li, M.; Chen, J.; Wang, X. Monitoring oxidative stability and changes in key volatile compounds in edible oils during ambient storage through HS-SPME/GC-MS. Int. J. Food Prop. 2017, 20, S2926-S2938. [CrossRef]

34. Arena, M.E.; Postemsky, P.; Curvetto, N.R. Accumulation patterns of phenolic compounds during fruit growth and ripening of Berberis buxifolia, a native Patagonian species. N. Z. J. Bot. 2012, 50, 15-28. [CrossRef]

35. Song, J.; Du, L.; Li, L.; Kalt, W.; Palmer, L.C.; Fillmore, S.; Zhang, Y.; Zhang, Z.; Li, X. Quantitative changes in proteins responsible for flavonoid and anthocyanin biosynthesis in strawberry fruit at different ripening stages: A targeted quantitative proteomic investigation employing multiple reaction monitoring. J. Proteom. 2015, 122, 1-10. [CrossRef]

36. Yeh, S.Y.; Huang, F.C.; Hoffmann, T.; Mayershofer, M.; Schwab, W. FaPOD27 functions in the metabolism of polyphenols in strawberry fruit (Fragaria sp.). Front. Plant Sci. 2014, 5, 518. [CrossRef]

37. Parra-Palma, C.; Úbeda, C.; Gil, M.; Ramos, P.; Castro, R.I.; Morales-Quintana, L. Comparative study of the volatile organic compounds of four strawberry cultivars and it relation to alcohol acyltransferase enzymatic activity. Sci. Hortic. 2019, 251, 65-72. [CrossRef]

38. Ulrich, D.; Olbricht, K. A search for the ideal flavor of strawberry-Comparison of consumer acceptance and metabolite patterns in Fragaria $\times$ ananassa Duch. J. Appl. Bot. Food Qual. 2016, 89, 223-234.

39. Fan, Z.; Plotto, A.; Bai, J.; Whitaker, V.M. Volatiles Influencing sensory attributes and bayesian modeling of the soluble solidssweetness relationship in strawberry. Front. Plant Sci. 2021, 12, 640704. [CrossRef]

40. Oh, Y.; Barbey, C.R.; Chandra, S.; Bai, J.; Fan, Z.; Plotto, A.; Pillet, J.; Folta, K.M.; Whitaker, V.M.; Lee, S. Genomic characterization of the fruity aroma gene, FaFAD1, reveals a gene dosage effect on $\gamma$-decalactone production in strawberry $($ Fragaria $\times$ ananassa $)$. Front. Plant. Sci. 2021, 12, 639345. [CrossRef] [PubMed]

41. Jetti, R.R.; Yang, E.; Kurnianta, A.; Finn, C.; Qian, M.C. Quantification of selected aroma-active compounds in strawberries by headspace solid-phase microextraction gas chromatography and correlation with sensory descriptive analysis. J. Food Sci. 2007, 72, S487-S496. [CrossRef] [PubMed]

42. Fan, Z.; Hasing, T.; Johnson, T.S.; Garner, D.M.; Schwieterman, M.L.; Barbey, C.R.; Colquhoun, T.A.; Sims, C.A.; Resende, M.F.R.; Whitaker, V.M. Strawberry sweetness and consumer preference are enhanced by specific volatile compounds. Hortic. Res. 2021, 8, 66. [CrossRef] 